\title{
Molecular Characterisation of Clostridium perfringens Type D Isolated from Sheep in Kashmir Himalayas, India
}

\author{
Z.A. Kashoo, S.A. Wani, A.H. Wani*, S.M. Khan, S. Qureshi, I. Hussain, \\ S. Farooq and J.A. Malla
}

Niche Area of Excellence, Anaerobic Bacteriology laboratory, Division of Veterinary Microbiology and Immunology, Faculty of Veterinary Sciences and Animal Husbandry, SKUAST-Kashmir, Shuhama, Srinagar-190006, India

*Corresponding author

\section{A B S T R A C T}

Keywords

Clostridium perfringens, Enterotoxaemia, Toxinotype, $16 \mathrm{~S}$ rRNA, Multiplex PCR, cpa, cpb, etx.

Article Info

Accepted:

20 July 2018

Available Online:

10 August 2018
The molecular characterization of Clostridium perfringens in sheep for various toxinotypes was investigated in this study. A total of 147 samples collected from healthy, diarrhoeic animals and morbid material of animals suspected to have died of enterotoxaemia were screened for Clostridium perfringens ( $C$. perfringens) toxinotypes. The polymerase chain reaction (PCR) amplification of $16 \mathrm{~S}$ rRNA gene revealed that out of 147 samples collected, 92 (62.58\%) were found positive for $C$. perfringens. All the 92 isolates were screened for three toxin genes viz., $c p a, c p b$ and $e t x$ using a multiplex PCR. Toxinotyping revealed that $65(72.65 \%)$ were positive for Clostridium perfringens Type A and 27 (29.34\%) were that of Clostridium perfringens Type D None of the isolates was found to be toxinotype B or $\mathrm{C}$.

\section{Introduction}

Clostridium perfringens is one of the ubiquitous organisms among clostridial species. It is the common inhabitant of gastrointestinal tract of humans and animals and also occurs in the soil. It is relatively aerotolerant, spore forming, non-motile, Grampositive rods $(0.6-0.8 \times 2-4 \mu \mathrm{m})$. The spores are oval, sub-terminal and bulge from the mother cell (Prescott et al. 2016). On the basis of four major toxins viz., alpha [CPA], beta [CPB], epsilon [ETX], and iota [ITX] the $C$. perfringens is divided into five toxinotypes i.e., A, B, C, D and E. The toxinotypes were distinguished using mouse lethality tests and checking sero-protection with neutralizing antibodies raised against culture supernatants of the representative $C$. perfringens toxinotype (Sterne and Batty, 1975). The toxin production 
depends on the specific toxinotype while all isolates of $C$. perfringens from animals produce alpha-toxin (CPA), and more than 98\% produce theta toxin, also known as perfringolysin O (Songer, 1996). The specific toxins are responsible for the clinical signs and a syndrome attributable to each type. The specific enteric infections of various animal species are associated to different toxinotypes (Ohtani and Shimizu. 2016, Ashgan. 2013)

The $C$. perfringens toxinotype $\mathrm{D}$ produces alpha and epsilon toxins and is responsible for ovine enterotoxaemia and caprine enterocolitis. Enterotoxaemia is an acute, highly fatal intoxication that affects sheep, lambs, kids and goats. Sheep of all ages are affected by enterotoxaemia, but lambs under 10 weeks of age are most susceptible as they are nursed by heavy-lactating ewes and the weaned lambs on lush pasture or in feedlots (Songer, 1996).

In 2010-11, livestock generated a total of $4 \%$ of the GDP and $26 \%$ of the agricultural GDP in India. Sheep rearing is considered to be one of the major contributors to the livestock sector. The economics of sheep farming depends largely on the survival of the lambs and later lambing percentage of adult stock. A study showed that enterotoxaemia (incidence rate- $1.5 \%$, death rate- $2.4 \%$ and case fatality rate-30.8\%) comes next to diseases like blue tongue, PPR, and anthrax with respect to incidence and death rate in India (Singh and Prasad. 2009). The prevalence rates of enterotoxaemia due to $C$. perfringens toxinotype $\mathrm{D}$ ranging between $24.13 \%$ and $100 \%$ have been reported and the disease is considered one of the most frequently occurring diseases of sheep and goats worldwide (El Idrissi and Ward. 1992, Greco. 2005).

The present study investigated the prevalence of Clostridium perfringens (C. perfringens), in sheep and goats of Kashmir valley as well as characterized the genotype of its isolates. This study documented the presence of $C$. perfringens toxinotype $\mathrm{A}$ and $\mathrm{D}$ in sheep and goats in Kashmir valley.

\section{Materials and Methods}

\section{Samples}

A total of 147 samples comprising of faecal material, intestinal contents, kidneys and abomasum pieces were collected from sheep. Out of the 147 samples, 105 faecal materials were from healthy, 36 faecal materials from diarrhoeic animals and 6 were from carcasses. The samples were collected in sterile vials from animals of different age groups.

\section{Isolation and identification of $C$. perfringens}

For isolation of $C$. perfringens, samples were inoculated in Difco ${ }^{\mathrm{TM}}$ Cooked meat medium (Becton, Dickinson and Company, Sparks, MD, USA) and incubated anaerobically in 3.5 litre anaerobic jar (Oxoid Limited, Thermo Fisher Scientific Inc., UK) with GasPak $^{\mathrm{TM}}$ Anaerobe Container System (Becton, Dickinson and Company, Sparks, $\mathrm{MD}$, USA) at $37^{\circ} \mathrm{C}$ for $24 \mathrm{hrs}$. Enriched samples were streaked on Sulphite Polymixin Sulphadiazine agar plates (SPS HiVeg ${ }^{\mathrm{TM}}$ Agar, Modified; Hi-Media laboratories, Mumbai, India) and the plates were incubated anaerobically at $37^{\circ} \mathrm{C}$ for $24 \mathrm{hrs}$. After incubation suspected colonies were subcultured on the SPS agar plates until they were free from contaminating bacteria. The pure cultures of $C$. perfringens toxinotypes were lyophilized for future use in the laboratory using $0.25 \mathrm{M}$ sucrose as cryoprotectant.

Confirmation of the isolates was done by demonstration of the typical cellular morphology in Gram's stained smear, standard 
biochemical tests and detection of $C$. perfringens by species specific polymerase chain reaction (PCR) using $16 \mathrm{~S}$ rRNA gene primers.

\section{Molecular characterization of $C$. perfringens isolates}

\section{Bacterial DNA isolation}

Suspected isolated colonies from agar plates were suspended in $1.5 \mathrm{ml}$ microcentrifuge tubes containing $100 \mu \mathrm{l}$ of distilled water by gentle vortexing. The samples were boiled for 5 min, cooled on ice for $10 \mathrm{~min}$ and centrifuged at $10,000 \times g$ in a table-top microcentrifuge (Cooling Centrifuge, Eppendorf 5418R, Hamburg, Germany) for 1 min. Three microlitres $(\mu \mathrm{l})$ of the supernatant was used as the template for PCR.

\section{Polymerase chain reaction}

All the PCR assays in this study were performed in $25 \mu \mathrm{l}$ reaction volume in Mastercycler gradient (Eppendorf AG, Hamburg, Germany). The reaction consisted of $3.0 \mu 1$ template DNA, $2.5 \mu 1$ of $10 \mathrm{X}$ buffer, $0.2 \mu \mathrm{l}$ of $25 \mathrm{mM}$ dNTP mix, $1 \mathrm{U}$ of Taq DNA Polymerase (Fermentas Life Sciences) and sterile distilled water. The $\mathrm{MgCl}_{2}$ was used at $2.0 \mathrm{mM}$ concentration, unless otherwise indicated. Sterilized distilled water was used as negative controls. All the primers were acquired from GCC Biotech, Kolkata, India.

\section{S rRNA gene amplification}

After identification of $C$. perfringens by phenotypic characteristics like colony characteristics, Gram's staining, the isolates were further confirmed using species-specific primers (Table 1) targeting 16S rRNA gene of the $C$. perfringens. The PCR conditions consisted of initial denaturation at $95^{\circ} \mathrm{C}$ for 15 min, followed by 35 cycles of denaturation at $94^{\circ} \mathrm{C}$ for $30 \mathrm{sec}$, annealing at $49^{\circ} \mathrm{C}$ for $90 \mathrm{sec}$ and extension at $72^{\circ} \mathrm{C}$ for $90 \mathrm{sec}$. This was followed by final extension at $72^{\circ} \mathrm{C}$ for 10 min. The DNA of $C$. perfringens Type D isolate obtained from Sheep Husbandry Department was used as positive control.

\section{Multiplex PCR of virulent genes}

All the $C$. perfringens isolates were screened for three different toxin genes using a multiplex PCR. These three toxin genes include $\alpha$-toxin $(c p a), \beta$-toxin $(c p b)$ and $\varepsilon^{-}$ toxin (etx). The primers used for the amplification of the genes are shown in Table 1. The PCR conditions were similar to that used for amplification of $16 \mathrm{~S}$ rRNA gene except for the annealing temperature that was set at $53^{\circ} \mathrm{C}$. The amplified products were electrophoresed in $1.5 \%$ agarose gel (Sigma Aldrich, St. Louis, USA) and stained with ethidium bromide $(0.5 \mu \mathrm{g} / \mathrm{ml})$. Amplified bands were visualised and photographed under UV illumination (Ultra Cam Digital Imaging, Ultra. Lum. Inc., Claremont, CA).

\section{Results and Discussion}

From 147 samples collected from sheep, 92 $(62.58 \%)$ carried $C$. perfringens. All the 92 isolates were morphologically and biochemically identified by Gram staining, capsular staining, lecithenase activity on egg yolk agar media, triple sugar iron (TSI) test and formation of double zone of haemolysis on 5\% sheep blood agar (Fig. 1) as $C$. perfringens. These isolates amplified $481 \mathrm{bp}$ product (Fig. 2) corresponding to $C$. perfringens.

Out of a total of 92 isolates from sheep, 65 $(70.65 \%)$ were found to carry cpa gene alone as a major toxin gene, thus were designated as toxinotype A. While the remaining 27 (29.34\%) harboured both cpa and etx genes, thus were designated as toxinotype D. None of 
the isolates carried $c p b$ gene indicating the absence of $C$. perfringens toxinotype $\mathrm{B}$ or $\mathrm{C}$ in sheep samples (Fig. 3). The $C$. perfringens isolates were characterized for important virulence factors including $c p a, c p b$ and $e t x$. Among lambs the occurrence of toxinotype D (55.76\%) was higher than that of toxinotype A (Table 2). Among adult sheep occurrence of toxinotype A $(60 \%)$ was higher than that of toxinotype D. Clostridium perfringens toxinotypes are responsible for varied disease syndromes in livestock animals and poultry. In the present study, healthy as well as suspected sheep populations from different regions of Kashmir valley were screened for the presence of $C$. perfringens toxinotypes. Our findings revealed that $92(62.58 \%)$ of 147 samples from sheep were positive for $C$. perfringens based on isolation and PCR amplification of
16S rRNA gene. In accordance with our study, a lower occurrence of $24.13 \%$ of $C$. perfringens in sheep of Morocco (el Idrissi and Ward. 1992) while as a higher prevalence of $100 \%$ of $C$. perfringens in sheep of Italy (Greco. 2005) has been recorded. Similarly, prevalence of $59.62 \%$ of $C$. perfringens in sheep was reported in Andhra Pradesh, India (Kumar. 2014)[9]. The prevalence of $96.92 \%$ of $C$. perfringens in sheep and goats in Switzerland has been reported (Miserez. 1998). Recent reports by Rasool et al. (2017) reported prevalence of $C$. perfringens to the tune of $44.94 \%$ from sheep in Kashmir valley where type A was most prevalent corroborating with our study. Similar study in this region by Nazki et al. (2017) reported prevalence of $72.36 \%$ from sheep.

Table.1 List of primers used in PCR for amplification of Clostridium perfringens toxin Genes

\begin{tabular}{|c|c|c|c|c|c|}
\hline S. No. & $\begin{array}{l}\text { Target } \\
\text { gene }\end{array}$ & Primer Sequence $\left(5^{\prime}-3^{\prime}\right)$ & $\begin{array}{l}\text { Primer } \\
\text { conc. } \\
(\mu \mathrm{M})\end{array}$ & $\begin{array}{l}\text { Product size } \\
\quad \text { (bp) }\end{array}$ & Reference \\
\hline 1. & 16S rRNA & $\begin{array}{l}\text { F-TAACCTGCCTCATAGAGT } \\
\text { R- TTTCACATCCCACTTAATC }\end{array}$ & 0.4 & 481 & $\begin{array}{l}\text { Tonookaet al. } \\
\text { (2005) }\end{array}$ \\
\hline 2. & сра & $\begin{array}{l}\text { F-GCTAATGTTACTGCCGTTGA } \\
\text { R-CCTCTGATACATCGTGTAAG }\end{array}$ & 0.4 & 324 & \multirow[t]{3}{*}{$\begin{array}{l}\text { van Astenet al } \\
\text { (2008) }\end{array}$} \\
\hline 3. & $c p b$ & $\begin{array}{l}\text { F-GCGAATATGCTGAATCATCA } \\
\text { R-GCAGGAACATTAGTATATCTTC }\end{array}$ & 0.4 & 195 & \\
\hline 4. & etx & $\begin{array}{c}\text { F-TGGGAACTTCGATACAAGCA } \\
\text { R-AACTGCACTATAATTTCCTTTTC } \\
\text { C }\end{array}$ & 0.4 & 376 & \\
\hline
\end{tabular}

Table.2 Details of the isolates of $C$. perfringens from adult sheep and lambs

\begin{tabular}{|c|c|c|c|c|c|}
\hline $\begin{array}{l}\text { Age } \\
\text { Group }\end{array}$ & $\begin{array}{l}\text { Healthy/ } \\
\text { Diarrhoeic }\end{array}$ & $\begin{array}{l}\text { No. of samples } \\
\text { screened }\end{array}$ & $\begin{array}{c}\text { Number } \\
\text { positive for } \\
C . \\
\text { perfringens }\end{array}$ & Type A & Type D \\
\hline \multirow[t]{2}{*}{ Adult } & Healthy & 59 & 33 & 21 & 12 \\
\hline & Diarrhoeic & $10+1 *=11$ & 7 & 3 & 4 \\
\hline \multirow[t]{3}{*}{ Young } & Healthy & 46 & 28 & 15 & 13 \\
\hline & Diarrhoeic & $26+5^{*}=31$ & 24 & 8 & 16 \\
\hline & & 147 & 92 & 47 & 45 \\
\hline
\end{tabular}

*caracass samples 
Fig.1\&2 Double zone of hemolysis produced by $C$. perfringens on sheep blood agar \& Amplicons of 16S rRNA gene based PCR
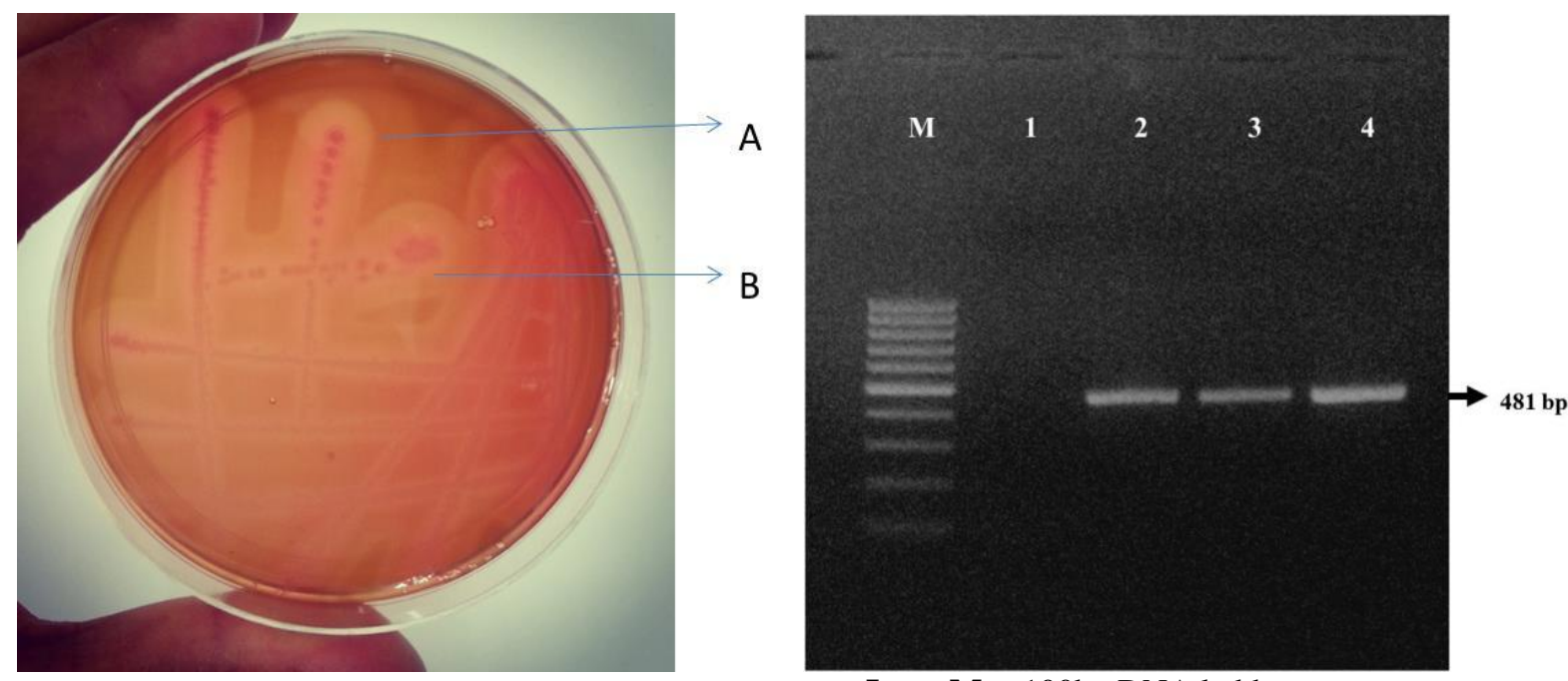

Lane M: 100bp DNA ladder

Lane 1: Negative control

Lane 2: Positive control

Lanes 3-4: Isolates positive for $C$. perfringens

Fig.3 Multiplex PCR amplicons of different virulence genes of Clostridium perfringens

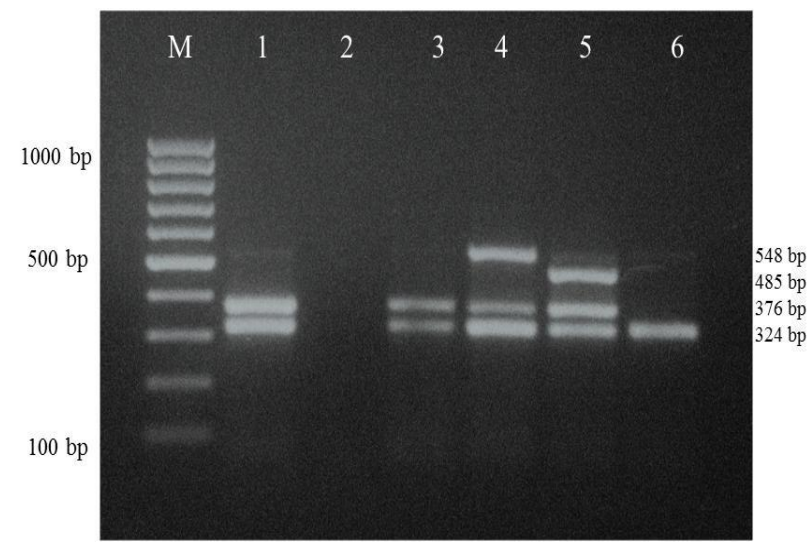

Lane M: 100bp DNA ladder

Lane 1: Positive control of $C$. perfringensType D with amplified cpa(324bp) and etx(376bp) genes. Lane 2: Negative control, Lane 3: C. perfringensType D,

Lane 4: $\quad$ C. perfringensType D with amplified cpa,etx and beta2(548bp) genes

Lane 5: C. perfringens Type D with amplified cpa,etx and cpe(485bp) genes

Lane 6: $\quad$. perfringens Type A with cpagene amplification

In the present study, $C$. perfringens toxinotype $\mathrm{D}$ was more prevalent among lambs $(56.16 \%)$ than adult sheep. Our findings are in agreement with Redostitis et al. (2007), who reported that enterotoxaemia is more prevalent in lambs aged between 3-8 weeks, in fattening lambs in United Kingdom. The authors attributed it to the heavy feeding and milking of lambs by ewes that are grazed on lush pastures. However, they also observed 
its higher prevalence in adult animals grazed on luxurious pastures. The spillover of the carbohydrate and protein rich nutrients into the small intestine from the abomasum encourages rapid multiplication of organisms and production of ETX. The increased prevalence of $C$. perfringens Type D $(21.65 \%)$ in lambs than healthy adult sheep (3.7\%) has been reported in Andhra Pradesh, India (Kumar. 2014). Recent studies by Rasool et al. (2017) and Nazki et al. (2017) also reported that majority of type D isolates were from diarrhoeic lambs occurrence of $58.6 \%$ and $56.16 \%$ respectively of type D isolates which endorse our results. Clostridium perfringens isolates obtained in this study were screened for presence of three toxin genes viz., $c p a, c p b$ and etx. Out of 92 isolates from sheep, $65(70.65 \%)$ were found positive only for cpa toxin gene, thus belonged to toxinotype A, while the 27 (29.34\%) carried both cpa and etx toxin genes thus belonged to toxinotype D. None of these isolates possessed $c p b$ toxin gene, indicating absence of $C$. perfringens toxinotype B or C. These findings are in agreement with the observations reported from the Italy in which $84 \%$ of $C$. perfringens isolated from the lambs and kids in Italy is toxinotype A and the remaining $16 \%$ as toxinotype $\mathrm{D}$ and none belonged to type B, C or E (Greco. 2005). In India $69.29 \%$ prevalence of enterotoxaemia from suspected sheep flocks and $39.71 \%$ from healthy sheep flocks has been reported (Kumar. 2014). Genotyping of the isolates from healthy animals indicated the presence of toxinotype A and D to be $45.56 \%$ and $31.64 \%$, respectively. Although, toxinotype C has not been reported from sheep in the present study, the presence of toxinotype B or $C$ cannot be ruled out owing to the fact the study being preliminary and based comparatively on small sample size.

In conclusion, this study documents the prevalence, isolation and characterization of
C. perfringens toxinotype $\mathrm{D}$ in sheep of Kashmir valley. The study concluded that, $C$. perfringens was prevalent among lambs in Kashmir valley and toxinotype A being most prevalent toxinotype in sheep. Absence of toxinotypes $\mathrm{B}$ and $\mathrm{C}$ in this study does not indicate the absence of these toxinotypes in the sheep population as the number of samples was comparatively less. The present work also made local strains of $C$. perfringens available for formulation of vaccine, to effectively control the menace in the state.

\section{References}

Ashgan, M., Al-Arfaj, A.A. and Moussa, I. 2013. Identification of four major toxins of Clostridium perfringens recovered from clinical specimens. African Journal of Microbiology Research, 7: 3658-3664

El Idrissi, A.H. and Ward, G.E. 1992. Evaluation of enzyme-linked immunosorbent assay for diagnosis of Clostridium perfringens enterotoxemias. Veterinary Microbiology, 31(4): 389-396.

Greco, G., Madio, A., Buonavoglia, D., Totaro, M., Corrente, M., Martella, V. and Buonavoglia, C. 2005. Clostridium perfringens toxin-types in lambs and kids affected with gastroenteric pathologies in Italy. The Veterinary Journal, 170: 346-50.

Kumar, N.V., Sreenivasulu, D. and Reddy, Y.N. 2014. Prevalence of Clostridium perfringens toxin genotypes in enterotoxemia suspected sheep flocks of Andhra Pradesh. Veterinary World 7: 1132-6.

Miserez, R., Frey, J., Buogo, C., Capaul, S., Tontis, A., Burnens, A. and Nicolet, J. 1998. Detection of alpha- and epsilontoxigenic Clostridium perfringens Type D in sheep and goats using a DNA amplification technique (PCR). 
Letters in Applied Microbiology., 26: 382-386.

Nazki, S., Wani, S.A., Parveen, R., Ahangar, S.A., Kashoo, Z.A., Hamid, S., Dar, Z.A., Dar, T.A., and Dar, P.A. 2017. Isolation, molecular characterization and prevalence of Clostridium perfringens in sheep and goats of Kashmir Himalayas, India. Veterinary World 10: 1501-1507.

Ohtani, K. and Shimizu, T. 2016. Regulation of toxin production in Clostridium perfringens. Toxins (Basel), 8: 207

Prescott, J.F., Uzal, F.A., Songer, J.G. and Popoff M.R. 2016. Brief Description of Animal Pathogenic Clostridia. Clostridial Diseases of Animals, Pp. 13-9.

Rasool, S., Hussain, I., Wani, S.A., Kashoo, Z.A., Beigh, Q., Nyrah, Q., Nazir, N., Hussain, T., Wani, A.H. and Qureshi,
S. 2017. Molecular Typing of Clostridium perfringens Isolates from Faecal Samples of Healthy and Diarrhoeic Sheep and Goats in Kashmir, India. International Journal of Current Microbiology and Applied Sciences 6: 3174-3184.

Redostitis, O.M., Gay, C.C., Hinchcliff, K.H. and Constable, P.D. 2007. Veterinary Medicine. 10th ed. Saunders Elsevier, London. p. 773-9.

Singh, B. and Prasad S. 2009. A model based assessment of economic losses due to some important diseases in sheep in India. Indian Journal of Animal Science 79: 1265-1268.

Songer, J.G. 1996. Clostridial enteric diseases of domestic animals. Clinical microbiology reviews 9: 216-34.

Sterne, M. and Batty, I. 1975. Pathogenic Clostridia. Butterworth \& Co.

\section{How to cite this article:}

Kashoo, Z.A., S.A. Wani, A.H. Wani, S.M. Khan, S. Qureshi, I. Hussain, S. Farooq and Malla, J.A. 2018. Molecular Characterisation of Clostridium perfringens Type D Isolated from Sheep in Kashmir Himalayas, India. Int.J.Curr.Microbiol.App.Sci. 7(08): 3682-3688.

doi: https://doi.org/10.20546/ijcmas.2018.708.373 